\title{
LA EXCLUSIÓN DEL CUERPO EN SEIN UND ZEIT Y LA NEGACIÓN DE UNA FENOMENOLOGÍA DEL CUERPO EN EL PENSAMIENTO DE HEIDEGGER ${ }^{1}$
}

\author{
FELIPE JOHNSON \\ Universidad de La Frontera (Chile)
}

\begin{abstract}
RESUMEN: Mediante una reflexión acerca de la ausencia de una tematización detallada del cuerpo humano en Sein und Zeit y atendiendo a la negación de una "fenomenología del cuerpo" en Zollikoner Seminare, el presente artículo se propone desarrollar la advertencia metódica que subyace a las discusiones de Heidegger sobre la corporalidad humana. En este contexto, se destacará la incompatibilidad que hay entre el modo de ser del Dasein, y el modo de ser que configura la interpretación tradicional del cuerpo, esto es, el cuerpo en cuanto cosa. A partir de lo anterior, se destacará la necesidad de atender a la pertenencia ontológica del fenómeno del cuerpo al Ser de lo Humano en el intento de desplegar una consideración existencial de la corporalidad humana.
\end{abstract}

PALABRAS CLAVE: cuerpo humano, fenomenología, Vorhandensein, Dasein, Heidegger.

\section{The exclusion of the body in Sein und Zeit and the denial of a phenomenology of the body in Heidegger's thought}

\begin{abstract}
Through a reflection on the lack of a detailed thematization of the human body in Sein und Zeit and, considering the denial of a "phenomenology of the body" in Zollikoner Seminare, this paper aims to develop the methodical advice behind Heidegger's treatment of human corporality. In this context, we will emphasize the incompatibility between the kind of being of Dasein and the kind of being that make up the traditional interpretation of the body: the body as a thing. Based on the foregoing, this study will discuss on the necessity to concentrate the attention on the ontological belonging of the body to the being of human being by the attempt to deploy an existential consideration of human corporality.
\end{abstract}

KEY WORDS: human body, phenomenology, Vorhandensein, Dasein, Heidegger.

\section{La EVENTUAL NEGACión DEL CUERPO Y DE SU TRATAMIENTO FENOMENOLÓGICO}

La tarea que nos hemos propuesto a continuación es esbozar la posibilidad de pensar nuestro cuerpo existencialmente en los términos en los que Heidegger habría realzado los caracteres fundamentales del Dasein en su analítica existencial. Ciertamente, para cualquier lector de su obra fundamental, Sein und Zeit, esto puede parecer una tarea del todo inapropiada, pues en ésta no sólo fueron dedicadas pocas líneas a la corporalidad, sino porque las veces en que esto ocurre pareciera que el problema del cuerpo no podría tener cabida en una consideración en buen sentido de los caracteres fundamentales del existir ${ }^{2}$. Asimismo, esta negación del cuerpo pareciera confirmarse más aún si es que quisiéramos ahora, pese a lo anterior, insistir en desplegar un tipo de consideración positiva acerca del mismo ateniéndonos a su pensamiento y nos resolviéramos a sistematizarlo bajo el título «fenomenología del cuerpo». Si este fuera el caso, advertiríamos

\footnotetext{
1 El presente artículo forma parte de la investigación FONDECYT de Iniciación n 11110087: «El fenómeno del cuerpo a la luz del Dasein: existencia y concretud en el pensamiento de Heidegger».

2 Respecto a la discusión crítica y especializada sobre la ausencia del cuerpo en Sein und Zeit es relevante atender a las observaciones de FRANCK (1986) y GREISCH (1994).
} 
que años más tarde, en 1963, en una de las sesiones realizadas por Heidegger junto a un grupo de psiquiatras convocados por Medard Boss, en la ciudad de Zollikon, Suiza, se transcribe: "No hay en realidad una fenomenología del cuerpo, porque nuestro cuerpo vivo (Leib) no es un cuerpo cósico (Körper). Con tal tema ya se ha errado respecto al asunto (Sache)»(1994a, p. 231) ${ }^{3}$.

Nos encontramos, de esta manera, con dos negaciones respecto al problema del cuerpo humano. Primero, respecto al problema de la corporalidad misma y a su inclusión en la analítica del Dasein y, segundo, en relación a la posibilidad de un análisis fenomenológico existencial, y ambas en períodos muy distintos del pensamiento de Heidegger ${ }^{4}$. Ciertamente, esto podría llevar a pensar que para éste el tema del cuerpo definitivamente debe quedar excluido de las consideraciones acerca del existir. Como vemos, la primera negación excluye al cuerpo de la analítica del Dasein, mientras que la segunda, anula la posibilidad de una línea de investigación a la cual pudiésemos llamar «fenomenología del cuerpo». En otras palabras, la negación del cuerpo como campo de investigación parece dejar de lado inmediatamente la posibilidad de un estudio programático de dicho fenómeno.

Cabe plantear la pregunta, no obstante, si es que aún así podríamos obtener alguna ganancia de las negaciones referidas y si, en efecto, éstas pueden convertirse, pese a todo, en una oportunidad de pensar nuestro cuerpo desde aquella perspectiva existencial que Heidegger establecería como el modo radical de ejercer la misma filosofía, o si éstas no hacen más que anular definitivamente una consideración estrictamente existencial de la corporalidad. Es importante mencionar, sin embargo, que el hecho de entender esta segunda opción de modo concluyente no parece atender del todo al modo de proceder del mismo Heidegger, si se toma en cuenta que, no obstante las negaciones referidas, éste emprende efectivamente una caracterización positiva de la corporalidad en Zollikoner Seminare. Precisamente, esto guarda estrecha relación con las presentes discusiones, en cuanto se advierte que para Heidegger, en todo momento de sus análisis, se trata de ganar una orientación y una aclaración del modo cómo abordar la corporalidad en un sentido positivo, vale decir, sus discusiones se detienen principalmente en precisiones de carácter metódico.

Pues bien, a nuestro juicio, la tarea de obtener alguna lección de las negaciones antes comentadas podría traducirse, en efecto, en un aporte en vistas a una consideración positiva sobre la corporalidad desde el pensamiento de Heidegger. En este contexto, en las presentes reflexiones nos preguntaremos si es que efectivamente ambas no son, en su sentido propio, más bien dos advertencias metódicas que intentarían, por su parte, dirigir el estudio de nuestra corporalidad en una dirección particular de tematización, en cuyo caso sí se haría posible su consideración sistemática. En lo que sigue, por tanto, nos proponemos mostrar cómo es que bajo estas dos negaciones, tanto aquella referida al fenómeno del cuerpo como a su propio estudio, permanece implícita una advertencia fundamental y que se expresa como la exigencia de una reformulación del modo cómo entender el cuerpo humano antes de tematizarlo y del modo cómo éste ha de ser expuesto programáticamente desde una fenomenología existencial. Por tanto, estas negaciones implicarían una aclaración del genuino método, del camino propio que ha de recorrer el pensar para hacer explícito un fenómeno que ante todo nosotros mismos somos.

3 Las traducciones de las citas transcritas en el presente artículo fueron realizadas por el autor.

4 Cabe tener en cuenta que los años 60 corresponden al período del pensamiento de Heidegger denominado Kehre, el cual se caracteriza por una contraposición radical con la metafísica tradicional de Occidente y un esfuerzo por desarrollar un pensar del ser en cuanto evento (Er-eignis). 
Entonces bien, a continuación nos proponemos indagar en el sentido de la negación del cuerpo en Sein und Zeit, para comprender desde ahí, cómo es posible para Heidegger sostener más tarde que una así llamada «fenomenología del cuerpo» no sería más que un malentendido, con lo cual intentaremos mostrar cuál sería el puesto programático de un estudio positivo de la corporalidad humana en su pensamiento y, junto a ello, cuál sería la naturaleza de aquel malentendido que permite la negación del cuerpo en tanto objeto de estudio, como de un estudio del mismo, bajo el título de una «fenomenología del cuerpo».

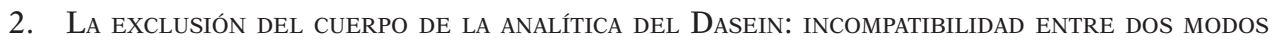
DE SER

Para quien el problema del cuerpo resulte ser fundamental en el contexto de una consideración radical de la existencia humana, la época de Sein und Zeit puede desconcertar por su eminente resistencia a la integración de la corporalidad en las reflexiones heideggerianas. En este respecto, cabe recordar las críticas a Heidegger por parte de pensadores tales como Plessner, Sartre o De Waelhens, quienes dieron por supuesto que los existenciarios realzados mediante la analítica del Dasein devienen de una idea de Hombre que no puede prescindir de su anclaje corporal en el mundo ${ }^{5}$. En efecto, aquellos momentos en los que se hace mención de la misma, se advierte de inmediato que ésta debe quedar al margen de una reflexión acerca de lo Humano, ya que, de lo contrario, esto implicaría que la aprehensión de su genuino modo de ser erraría. A continuación nos interesará aclarar cómo es que el problema de esta eventual exclusión no debe entenderse en el sentido de una cierta prohibición en relación a tratar un determinado tema, como si la analítica del Dasein prescribiera a la consideración filosófica cuáles serían aquellos tópicos que le son o no permitidos estudiar. Esta resistencia de incluir al cuerpo en un análisis del existir se enmarca en un problema eminentemente metódico, y esto quiere decir que la discusión se centra más bien en la tarea de aclarar cuál sería el sentido de una consideración estrictamente filosófica.

Desde ya, es significativo señalar, aunque de modo muy general, que el punto de partida desde el cual Heidegger asume la tematización filosófica es sumamente particular y atiende al sentido más propio de la fenomenología, esto es, a una confrontación estricta "con las cosas mismas», lo cual no señala sino a aquello que se manifiesta en tanto lo que es en una relación inmediata del vivir fáctico. Respecto a nuestro problema, esto quiere decir que aquello desde donde una consideración filosófica del cuerpo ha de comenzar es lo simplemente dado en el existir inmediato, vale decir, a partir del modo cómo nosotros fácticamente somos en sentido corporal ${ }^{6}$. Desde este punto de partida, la consideración deberá señalar momentos pertenecientes a un despliegue fáctico del

\footnotetext{
$5 \quad$ Precisamente, en Zollikoner Seminare (p. 292) se le menciona a HeIDEgGER la sorpresa con que Sartre habría tomado el hecho que sólo seis líneas hayan sido dedicadas a la corporalidad en Sein und Zeit. A la vez, es importante tener en cuenta el prefacio a Die Stufe des Organischen und der Mensch, donde Plessner (p. XIII) alude a la necesidad de un sustento orgánico del existir, descuidado, por lo demás, en el pensamiento de Heidegger. Asimismo, cabe atender al prólogo escrito por Alphonse de Waehlens a la Structure du comportement de Merleau-Ponty, donde nuevamente se destaca el anonimato del cuerpo en las estructuras existenciales realzadas por Heidegger (p. V). En este contexto, Hoffman (2006) describe convenientemente la posición desde la cual tanto Sartre como Merleau-Ponty reprocharon a Heidegger la omisión del cuerpo en Sein und Zeit.

6 Sobre una reflexión filosófica acerca del cuerpo a la luz de la vida fáctica, Cf. JoHnson, $2010, \S 11$.
} 
existir, lo cual implica un atenerse a un campo temático de una naturaleza muy distinta, por lo demás, a propiedades materiales, pues, no es lo mismo tematizar nuestro cuerpo en tanto objeto físico, que entender cómo es que éste se da en la ejecución misma de la vida inmediata. Justamente, es en este último nivel donde nos hallamos más próximos a un suelo primario desde el cual nuestro cuerpo podrá servir de inicio para una posterior tematización. Así es como vemos que el problema de fondo se refiere no sólo al modo de tematización que implica el problema de la corporalidad, sino a que los fenómenos en juego exigen modos particulares de trato y, desde esta perspectiva, la corporalidad, en su sentido tradicional, parte del entendido que ésta es una cosa material, mientras que el existir ha de entenderse como un movimiento de apertura del propio Ahí en y como el cual al existir le es dado ser ${ }^{7}$.

Considerando lo anterior, la pregunta que competería realizar respecto al problema del cuerpo vendría a ser: ¿cómo es que algo así como el organismo, es decir, aquel entramado de partes materiales que funcionan en conjunto de modo causal, puede entenderse como una instancia constitutiva de un fenómeno tan particular como es el de abrir el propio Ahí? Ciertamente, sería posible relacionar ambos ámbitos distinguiendo lo que ocurre a un nivel físico de lo que ocurre a un nivel psicológico o, podríamos decir, experiencial. En este sentido, primero deberían hallarse aquellos receptores sensibles para poder percibir un determinado objeto y, luego, al Hombre le estaría dado tener conciencia del mismo. La pregunta, empero, sigue siendo por el ámbito genuino donde efectivamente se desenvuelve el existir. Atendiendo a lo anterior, ¿podemos decir que vivimos encerrados en una esfera psicológica, virtual, mientras lo que realmente está ocurriendo son episodios físicos como roce o resistencia de cuerpos materiales que se confrontan con determinadas fuerzas?

Pues bien, atendamos a la siguiente observación de Heidegger: «Este ente, Dasein, no ha de ser experienciado o interrogado según su saspecto<, no en vistas a aquello de lo que se compone, no según partes y capas, que una cierta manera de considerar pueda encontrar en él» (1994b, p. 207). Entendiendo esta cita como una advertencia acerca del modo cómo una tematización del existir ha de realizarse, podemos entender, por lo pronto, que nuestro cuerpo, entonces, no puede ser aprehendido según su aspecto físico, su color o su figura, o en vistas a su magnitud. También resulta inapropiado considerarlo respecto a sus partes, como tronco, extremidades, etc.; en relación a las capas de la piel (epidermis, dermis, etc.), o a su composición anatómica, como son sus músculos, venas, arterias, nervios o huesos, pues, de esta manera, la tematización

\footnotetext{
Para evitar distraer las presentes discusiones del tema mismo de la corporalidad, es que nos permitimos formular la tesis heideggeriana amplia respecto al existir como aquello a lo que le es dado abrir y ser su propio espacio vital, esto es, su propio Ahí. De todos modos, es importante precisar que, mediante dicha expresión, entendemos que el sentido fundamental del Dasein es el de ser al modo de su aperturidad (Erschlossenheit). Dicho fenómeno es, por tanto, el principal al momento de comprender el fenómeno del existir humano. De hecho, tanto la «disposición afectiva» (Befindlichkeit), la «comprensión» (Verstehen), como el «hablar» (Rede), ampliamente tratados en el capítulo V de la Primera Sección de Sein und Zeit, se constituyen en la explicitación de los momentos propios que componen el fenómeno mismo de la apertura. Ahora bien, cabe recordar que el sentido rector del modo cómo dicha apertura abre el Ahí propio, es decir, cómo el Dasein se constituye, en última instancia, en su propio Ahí, abriéndolo y habitándolo fácticamente, será entendido como el cuidado (Sorge). El sentido primario de apertura del Ahí viene a ser, por tanto, estar en trabajo de concretarse en cuanto a la posibilidad (Sein-können) que de antemano se ha asumido ser. Desde dicho sentido de consecución de sí en cuanto poder ser, i.e., desde su carácter "previo», es que el Dasein, en definitiva, abre su mundo, siendo él mismo su Ahí, al modo de habitarlo en un trato determinado con los entes que en dicho Ahí descubre (Entdecktheit). Como se advierte, ésta es la razón por la cual el Dasein, en cuanto cuidado (Sorge), ha de comprenderse con carácter de futuro (Cf. HeIDEgGer, 2001, p. 220 s.).
} 
filosófica se volvería impotente de acceder al ámbito de carácter existencial de despliegue, esto es, a aquello que se muestra como lo particular y genuino cuando mi cuerpo es efectivamente tal en el vivir fáctico. Esta consideración deberá, por tanto, ir más allá de los componentes señalados, en tanto todos ellos «describen» ónticamente algo que se despliega en tanto «cuerpo» según un sentido radicalmente distinto. Lo que está en juego en este caso no son aquellas características materiales o biológicas, sino el modo cómo el cuerpo, cuando auténticamente es nuestro cuerpo, vitalmente se ejecuta. Ese sentido eminente y rector presente cada vez que nuestro cuerpo es tal, es precisamente la esencia del cuerpo, su «sentido existencial». Se advierte, entonces, que este ámbito de tematización está muy lejos de explicitar caracteres abstraídos de una cosa física, ya que trata de la explicitación de un sentido de ser y de los momentos pertenecientes a dicho sentido.

Como podemos advertir, la explicitación filosófica encuentra, entonces, su tarea propia en la tematización de un sentido preponderante según el cual el ente es tal. En este contexto es que Heidegger advierte que lo que ha de ser realzado es aquella manera cómo está dado ser, la así denominada «Weise ızu sein`»(1994b, p. 207), siendo ésta, en cuanto la esencia del ente, su sentido particularmente característico. En el ejercicio de realce de este sentido rector radica, por tanto, el trabajo ontológico. No obstante, la tematización filosófica tradicional del cuerpo parece no haber emprendido dicha tarea, sino más bien parece haber comenzado asentada ya en un modo de ser implícitamente asumido. Dicho sentido asumido, por ende, subyace de antemano al modo de emprender una descripción de la corporalidad y esto se traduce en el realce de eventuales propiedades físicas y biológicas.

Así es como Heidegger puede parafrasear, en el sentido anteriormente expuesto, un modo de acceso inadecuado a la manera cómo al existir le es dado ser en su propio espacio vital: «El Ser-en en un mundo es una propiedad espiritual y la 'espacialidad' del Hombre es una cualidad de su corporalidad viva (Leiblichkeit), la cual siempre está »fundada«, a la vez, por la corporalidad cósica (Körperlichkeit)» (Heidegger, 2001, p. 56). En efecto, una caracterización de este tipo define al existir fáctico en un mundo, asumiendo una cualidad física, la cual vendría a aclarar su modo de hallarse en el espacio. Sin embargo, esta caracterización no se detiene a revisar el derecho de este eventual sustento físico, sino que la comprensión de un sustento cósico necesario a la vida para poder posicionarse en un mundo parece más bien subyacer a estas discusiones, de modo que una pre-comprensión implícita de una vida sostenida por una cosa, por el cuerpo físico, se constituye en la guía para consideraciones sobre el modo cómo el Hombre habitaría su mundo.

Mientras una determinada comprensión del cuerpo, por tanto, rige y otorga sentido a un hablar sobre el fenómeno, ésta permanece, a su vez, en un peligroso anonimato, en tanto puede resultar no ser la adecuada en vistas a una comprensión de lo que el cuerpo genuinamente es. Esto, por ende, implica que el pensar no se ha apropiado aún en su radicalidad de aquello con lo que trata. Entendiendo la corporalidad viva como fundada en la corporalidad cósica, permanece aún desatendido un nivel último de consideración cuyo sentido es el de acceder a lo efectivamente "fundante» para comprender su íntimo derecho. Entonces bien, el trabajo ontológico estricto aún no ha tenido lugar, sino que más bien éste se ha postergado.

Interesante resulta esta advertencia, ya que nos conduce a preguntarnos cuál es, por tanto, aquel sentido ontológico que domina aquellas consideraciones sobre la corporalidad que quedan excluidas de la analítica del Dasein. Como ya se ha visto, en la cita antes referida se vincula la corporalidad viva con la corporalidad cósica, lo que en alemán se 
expresa con los vocablos Leiblichkeit, para la primera, y Körperlichkeit, para la segunda. Dicho vínculo se formula al modo de una «fundación». ¿En qué sentido, pues, la Leiblichkeit se «funda» en la Körperlichkeit? Según como Heidegger lo entiende, una relación de fundación es aquella que rinde cuenta del modo cómo algo es como es (Cf. Heidegger, 1994a, p. 28), es decir, atendiendo a nuestro caso, dicha relación de fundación deberá aclarar cómo es que la corporalidad viva, entonces, podría llegar a ser entendida como una estructura orgánica que ocupa un espacio y un tiempo determinados.

La pregunta nos lleva, así, a plantearnos en qué radica un cuerpo objetual, lo cual en alemán se expresa mediante el vocablo «Körper». Como se sabe, la utilización de la palabra «Körper» es válida para toda cosa física, como cuando hablamos, por ejemplo, de «cuerpo», entendiendo todo objeto con determinadas dimensiones, incluyendo a entes vivos e inertes, en tanto presentan en sí mismos una masa, es decir, en tanto poseen dimensiones como el largo, el ancho y la profundidad. Vale decir, la corporalidad viva es descrita en términos físicos y biológicos, en la medida en que antes de nada se le entiende como "algo poseedor de masa", y por ende, se le comprende como algo caracterizado primariamente por caracteres de lo extenso. La corporalidad viva, en suma, es entendida en el sentido de la substancia extensa (Cf. Heidegger, 2001, p. 90). Con esto se destaca, entonces, el sustento ontológico de fondo. El ser de nuestro cuerpo, aquel que domina y dirige una tematización del mismo en tanto material, como ocurre en el contexto de los estudios biológicos, es, en última instancia, la extensión, esto es, un modo de ser que, en palabras de Heidegger, se caracteriza por encontrarse meramente ahí, presente, contenido por un espacio determinado, en otras palabras, lo que él mismo denomina Vorhandensein.

Ontología del cuerpo, es decir, una consideración filosófica de nuestra corporalidad, parece, según lo anterior, haber asumido una dirección de interpretación ciega a su principal tarea que es precisamente la de realzar aquel supuesto primario que la dirige para investigar su propio derecho. Ontología del cuerpo no viene a ser más que una ontología de la cosa (Dingontologie) ${ }^{8}$ (Cf. Heidegger, 2001, p. 100), de lo cual se desprende que su tarea principal se concreta en la explicitación, en sus caracteres propios, de un fenómeno que es asumido previamente como un objeto espacial, tal y como resulta ser todo otro ente del mundo natural. Así, el problema principal radica en que aquello que en este caso se considera primariamente como una cosa, y que desde esa óptica es realzado en sus caracteres particulares, no es sino un constitutivo del Hombre mismo, i.e., de un ente cuyo modo de ser, en el contexto de las interpretaciones heideggerianas, es radicalmente distinto al de una cosa. En efecto, lo Humano del Hombre se caracteriza por constituirse en la apertura del Ahí, del mundo, en donde recién pueden ser descubiertas dichas cosas, vale decir, aquellos entes que presentan tanto el modo de ser de la Vorhandenheit como de la Zuhandenheit («ser a la mano»), o, en otras palabras, lo que Heidegger, para distinguirlos del modo de ser del Dasein, denomina: el ente intramundano (innerweltliches Seiendes) (Cf. Heidegger, 2001, p. 183). En este contexto, y para delimitar el modo cómo el existir es efectivamente «en» su mundo, al modo de abrirlo y habitarlo, de un modo impropio, como es la noción de estar contenido en un determinado espacio geométrico, Heidegger señala: «El Ser-en, por el contrario, mienta una aprehensión del ser del Dasein y es un existencial. Luego, no se puede pensar en un mero estar presente (Vorhandensein) de un cuerpo-cosa (el cuerpo del hombre) »en " un ente meramente presente» (Heidegger, 2001, p. 54).

\footnotetext{
8 Respecto al contexto de la crítica a Descartes en el que tienen lugar estas observaciones heideggerianas y a sus directas implicancias en el problema del cuerpo, Cf. JoHNSON, 2009.
} 
¿Es posible, en suma, insistir en una tematización de nuestro cuerpo en el contexto de una explicitación del modo de ser del existir, cuando este último implica apertura de mundo, mientras que nuestra corporalidad es tradicionalmente considerada en el sentido de lo descubierto en dicha apertura? Con esta pregunta se hace explicito el descuido metódico central que subyace a una consideración tradicional del cuerpo y, por tanto, se rinde cuenta de la exclusión del mismo en la analítica del Dasein ${ }^{9}$ Sin embargo, la razón de la exclusión en cuestión no se agota con lo expuesto. La tematización del cuerpo como una «cosa meramente presente en un espacio» ha de ser considerada como la consecuencia de un supuesto ontológico de fondo. El mismo supuesto que, por lo demás, determina tradicionalmente otro componente del Hombre, esto es, el alma (Seele). La aprehensión tradicional del Hombre asume que éste es un ente compuesto por dos naturalezas, i.e., lo Humano radicaría en una síntesis de dos entidades, alma y cuerpo, las cuales, a su vez, poseen un ser autónomo y no requieren de algo distinto a ellas para manifestarse. Cuerpo y alma se entienden, en suma, como dos substancias, las cuales, en su conjunto, conformarían una unidad mayor como es el Hombre, por lo cual, la vida humana es asumida indirectamente en el sentido de la mera presencia espacial y, por tanto, cósicamente. En palabras de Heidegger: «Substancialidad es el hilo conductor ontológico para la determinación del ente, a partir del cual la pregunta por quién [es el existir] es respondida. El existir es aprehendido implícitamente de modo previo como una mero estar presente (Vorhandenes)» (Heidegger, 2001, p. 114).

Dicha incomprensión de lo Humano como lo constituido por una instancia cósica es expresada, en efecto, por Heidegger como cosa-hombre (Menschending) (Cf. Heidegger, 2001, p. 60), con lo cual se sugiere nuevamente que interpretar lo Humano a la luz del carácter de una cosa no puede sino desatender al asunto mismo. Por tanto, bajo el supuesto de la idea de ser en cuanto tal como substancia, se toma al Hombre como el resultado de la conjunción de dos componentes, lo cual deja en completa ambigüedad cuál es el modo de ser de la unidad misma que ambos sumatoriamente conforman: «Con ello se está nuevamente ante un Ser-estando-juntos (Zusammen-vorhanden-sein) de una cosa provista de espíritu con una cosa corporal, y el ser en cuanto tal del ente así compuesto permanece ante todo oscuro» (Heidegger, 2001, p. 56). Asimismo, el año de la publicación de Sein und Zeit, en el semestre de verano de 1927, en la lección Die Grundprobleme der Phänomenologie, Heidegger aborda, de modo más extenso, lo que podemos leer en el § 64 de Sein und Zeit. En el contexto de una crítica a la interpretación kantiana de la «subjetividad» y de la noción de "persona», leemos: «A pesar de que espíritu, alma y cuerpo, en sí mismos y en cada una de las distintas maneras, permanezcan determinados o indeterminados, no obstante, el todo del ente que nosotros mismos somos, cuerpo, alma, espíritu, la manera de ser de su totalidad originaria, permanece ontológicamente a oscuras» (Heidegger, 1997, p. 208) ${ }^{10}$.

\footnotetext{
9 Al respecto, relevante resulta el comentario de Malpas, quien justamente reprocha a Heidegger la vinculación que este hace del cuerpo vivo con el cuerpo extenso: «Heidegger's failure to take proper account of locatedness -and so of distance and orientation - is directly tied, therefore, to his inadequate treatment of the body. While the issue of embodiment is something that Heidegger recognizes, he seems effectively to consign the body (perhaps not surprisingly given the framework of his account) to the realm of Cartesian spatiality» (MALPAS, 2000, p. 221).

10 Cabe mencionar que Heidegger, junto a estas expresiones señala cómo es que en el pensamiento kantiano el «existir de la persona» (Dasein der Person) se explicita como el «existir de una cosa» (Dasein eines Dinges) (HeIdEgGer, 1997, p. 209). Significativo resulta, en este contexto, notar que Kant, a juicio de Heidegger, asumiría el siguiente supuesto en su articulación del concepto de "espíritu» en el sentido de una "psicología metafísica» (metaphysische Psychologie): «En tanto substancia, es decir, en tanto algo meramente presente (Vorhandenes) es dada el alma (Seele) en el sentido interno. Por esto es que ella es
} 
En suma, podemos afirmar que el principal descuido metódico de un acceso al cuerpo desde la mera presencia espacial se refiere al hecho que a éste se le entiende como perteneciente a un ente como es el Hombre, aunque al integrarlo en él, se le tematiza de acuerdo a un modo de ser extraño al mismo. Así, podemos decir que la inclusión del cuerpo en las consideraciones acerca del existir podría traer consigo el eventual peligro de inmiscuir consideraciones de dos modos de ser distintos para aclarar uno sólo, como es el del Ser Humano, es decir, el Dasein. En términos concretos, esto implica que, mientras el Dasein ha de ser tematizado como el movimiento de despliegue del Ahí que la vida humana habita, la inclusión del cuerpo, entendido éste en su sentido tradicional como un objeto material que ocupa un espacio y un tiempo determinados, parece conducir a dejar en el mismo nivel la tematización de meras cosas con fenómenos que no pueden ser cosificados, pues resultan ser más bien sentidos de la aperturidad misma y no objetos. Así, el principal riesgo de considerar al cuerpo en una explicitación del existir radica en hacer pasar un objeto como momento componente de un fenómeno tan particular como es el despliegue del espacio existencial. Por otra parte, la posibilidad de este descuido metódico radica en que al Hombre mismo se le intenta explicitar en un horizonte de ser ajeno, dejando en la más completa ambigüedad su genuino modo de ser: el existir. En definitiva, si tradicionalmente acaece una cosificación del cuerpo y, por ende, éste es entendido según el modo de ser del ente intramundano, es imposible que se le pueda integrar en el ejercicio metódico de explicitar un modo de ser que radica en la apertura de un mundo, es decir, la trascendencia. Mientras tanto, para desvincular una comprensión de lo Humano en cuanto Dasein de toda interpretación cosificante, Heidegger es enfático en advertir que "la 'Substancia' del Hombre no es el espíritu entendido como la síntesis entre alma y cuerpo, sino la Existencia» (Heidegger, 2001, p. 117).

Pues bien, atendiendo al malentendido metódico que impide una inclusión del cuerpo en la analítica del Dasein, estamos en condiciones de comprender, a continuación, por qué es que Heidegger puede negar entonces una así llamada «fenomenología del cuerpo».

3. La Negación de UNA FENOMENOLOGía del CUERPo: OlVIDO DE LA PERTENENCIA AL SER DE LO Humano

Atendamos, pues, a la razón expuesta por Heidegger en relación a que en realidad no haya algo así como una «fenomenología del cuerpo». La cita rezaba: «No hay en realidad una fenomenología del cuerpo, porque nuestro cuerpo vivo (Leib) no es un cuerpo cósico (Körper). Con tal tema ya se ha errado respecto al asunto (Sache)» (Heidegger, 1994a, p. 231).» Como se advierte, en tal afirmación se alude al hecho de que el cuerpo vivo (Leib) no es de carácter cósico y que, por lo mismo, una fenomenología del cuerpo no implicaría sino un error respecto al asunto que efectivamente ha de ser tratado. Nuevamente la distinción entre cuerpo cósico (Körper) y cuerpo vivo (Leib) resulta de interés para las presentes discusiones. Por lo demás, este es un aspecto que Heidegger parece ya haber desarrollado doce años después de Sein und Zeit, en la lección de 1939, titulada Nietzches Lehre vom Willen zur Macht als Erkenntnis, donde éste se detiene en la determinación fundamental de lo Humano que realiza Nietzsche en cuanto cuerpo.

lo contrario de lo dado mediante el sentido externo, lo cual está determinado como materia y cuerpo, es decir, el alma, entendida como lo que se dona mediante el sentido interno, es inmaterial» (HEIDEGGER, 1997, p. 203). 
Intentando desplegar el sentido de las consideraciones nietzscheanas, Heidegger comenta: "Si por cuerpo entendemos una masa de materia pesada, que rellena un espacio, entonces quizás el cuerpo vivo (Leib) es el »cuerpo cósico (Körper) de un ser vivo; pero lo que vive no 'tiene' un mero cuerpo cósico (Körper) en el sentido aludido, sino un cuerpo vivo (Leib), y quizás no sólo 'tiene' este cuerpo - lo que vive es corporal. Lo que vive, decimos bien, cuerpea y vive. Más exactamente: Lo que vive, vive, en la medida en que cuerpea» (Heidegger, 1989, p. 159).

Así, las consideraciones del cuerpo a partir de Nietzsche parecen proporcionar a Heidegger el enfoque inicial para esbozar una consideración de la corporalidad donde ésta ya no sea reducida a los caracteres geométrico-espaciales de una cosa extensa, lo cual ciertamente impediría su inclusión en una consideración del existir, como veíamos que ocurría en Sein und Zeit. Como se puede ver en el fragmento citado, el fenómeno del cuerpo vivo adquiere ahora otro tipo de caracterización. Éste se realza, por lo pronto, en sentido verbal. El ser vivo, afirma Heidegger, «cuerpea», es decir, «es leibt» y, por lo mismo, el cuerpo no sólo es «tenido» por un ente vivo, sino que, caracterizada verbalmente, su corporalidad viene a ser entendida más bien como un modo particular de ser del mismo, vale decir, el ser vivo es tal siendo de modo corporal.

Precisamente es esta perspectiva la que viene a ser desarrollada de modo algo más extenso en Zollikoner Seminare. En algunos protocolos del año 1965, el problema del cuerpo vuelve a expresarse en sentido verbal, como Leiben, es decir, como un «ser o estar siendo cuerpo". Pero es importante subrayar que dicho término no mienta un cuerpo vivo singular, sino más bien, con él parece hacerse explícito aquel modo específico cómo todo cuerpo particular ha de "ser cuerpo». Como se ve, una tematización sobre el cuerpo no puede, por tanto, tener por tarea la enumeración de características particulares de cuerpos observados, pues algo así como el fenómeno "cuerpo» no es un ente particular del cual se abstraigan características adquiridas mediante la observación. Lo que está en juego con el término verbal «Leiben» es más bien aquel modo de ser fundamental que domina todo aquello que denominemos «cuerpo»y, más aún, «nuestro cuerpo». El problema del cuerpo, entonces, expresado en cuanto «cuerpear» (Leiben), se refiere, en efecto, al realce de su esencia ${ }^{11}$.

Pues bien, con estas apreciaciones ya se puede advertir que el modo cómo un ente vivo es corporal no es indiferente a la naturaleza del mismo ente. Y en el caso del Hombre, podemos, entonces, decir que aquello que sea nuestro cuerpo deberá atender a nuestro carácter humano, evitando reducir lo corporal a meros procesos fisiológicos ejecutados por una cosa extensa. En efecto, este último tipo de consideración pasaría por alto el hecho fundamental de que todo cuerpo, en tanto responde a una manera específica de ser, es cuerpo en el horizonte del ser de dicho ente. En este sentido es que Heidegger debe señalar en Zollikoner Seminare que «el cuerpo es cada vez mi cuerpo» (Heidegger, 1994a, p. 113), con lo cual se hace énfasis en un aspecto fundamental para toda consideración del fenómeno, a saber, que su pertenencia a nosotros no es la de tener adherida a nuestra constitución una dimensión en esencia distinta a la nuestra. En este caso se trata más bien de una pertenencia fundamental, es decir, ontológica. En palabras de Heidegger: «Si el cuerpo en tanto cuerpo es cada vez mi cuerpo, entonces, esta manera de ser es la mía, así el cuerpear es co-determinado mediante mi Ser humano

11 En efecto, Heidegger advierte que «fenómeno» no mienta lo particular. En palabras suyas: «El fenómeno es la esencia (Wesen) de aquello que se muestra. El fenómeno, en tanto lo que se muestra desde sí, mienta siempre el ser del ente, no un particular que está siendo» (HeIDEGGER, 1994a, p. 221). 
(Menschsein) en el sentido de un estar ekstático en medio del ente abierto a la luz de la aperturidad (Lichtung)» (Heidegger, 1994a, p. 113).

Estas advertencias por parte de Heidegger ya son significativas para comprender el sentido propio de un eventual estudio sobre la corporalidad. En ellas no hay determinación alguna del contenido del fenómeno en cuestión, sino que se trata de consideraciones metódicas, es decir, de aquellas que delimitan de qué modo el fenómeno mismo ha de ser interrogado de manera que podamos entenderlo en su más genuino ser. Estas consideraciones son tan necesarias para el desarrollo de cualquier investigación, que en el caso que sean desatendidas, ésta correría el peligro de comprender su ente de estudio, en este caso, nuestra corporalidad, de un modo que no respetara su propia naturaleza. En el caso del cuerpo, esto implicaría comprenderlo como algo extenso, contenido por un espacio geométrico y delimitado de acuerdo a las dimensiones de su masa. Por tanto, el hecho de permanecer en este eminente desvío al momento de comprender nuestro cuerpo ha de ser la razón por la cual una tematización genuina del existir, es decir, de un modo de ser radicalmente distinto a lo cósico, debe resistirse a incluir la corporalidad.

Atendiendo, entonces, a la razón de la negación del cuerpo comentada en Sein und Zeit, la cual prescribe que nuestra corporalidad no ha de ser tratada como una instancia fundada en el modo de ser de la mera presencia espacial (Vorhandenheit), ahora parece indicarse que su consideración debe atenerse en estricto rigor al sentido auténtico del existir, es decir, al modo de ser al cual nuestro ser corporal pertenece en su auténtico fundamento. Pues bien, detengámonos ahora en la pertenencia indicada anteriormente entre nuestro ser-cuerpo (Leiben) y nuestro propio ser. A nuestro juicio, entender dicha pertenencia podrá llevarnos a comprender la eventual negación de una así llamada «fenomenología del cuerpo». Como se podrá apreciar, en este caso prescindimos de hablar de la pertenencia del «cuerpo a nosotros» para evitar una comprensión óntica de lo discutido y así poder reformular ahora el problema a la manera de una pertenencia del mismo a nuestro ser. Este justamente corresponde al modo del planteamiento del problema del cuerpo en el caso de Heidegger. Esta pertenencia se expresa, de hecho, en la determinación del cuerpo en sentido verbal. Porque el existir no es un mero estado, sino un movimiento mediante el cual nuestro propio espacio vital, nuestro propio Ahí y lo que en él descubrimos, se abre en vistas a la consecución de nosotros mismos como posibilidad. Y es que el cuerpo debe también ser comprendido en el horizonte de dicha dinamicidad, esto es, como un momento perteneciente al movimiento de dejarnos acaecer como un poder ser (Sein-können). Cuerpo, entonces, no es genuinamente una cosa, sino un carácter de la concreción de este poder ser, y, por ende, pertenece al sentido total del existir que Heidegger denominó cuidado (Sorge) (Cf. Heidegger, 2001, §41). No se trata, por tanto, de que mi cuerpo esté a mi servicio, como si fuese algo que yo no soy, como si fuese un útil, sino más bien, lo que acá se mienta es que mi cuerpo es mi cuerpo en la medida en que es parte de mi ser en cuanto soy en el trabajo de dejarme acaecer respecto a un poder ser previamente asumido, es decir, en cuanto nuestro existir tiene carácter de futuro. Este es el motivo por el cual Heidegger señala que los límites del cuerpo se modificarían de acuerdo a las situaciones específicas en las que habito, dejándome ser (Cf. Heidegger, 1994a, 113) ${ }^{12}$.

12 En este marco de discusiones se vuelve explícita la necesidad de abordar el fenómeno del cuerpo atendiendo al cuidado (Sorge), en tanto ser del Dasein. Como se advierte, dicha investigación dirigirá la tematización del cuerpo a un tratamiento temporal, entendido como una consideración que, respecto al privilegio que otorga Heidegger a la temporalidad en la analítica existencial, se constituiría en aquella tematización propiamente radical de nuestro fenómeno. Para la clarificación del cuidado en el contexto del tiempo, Cf. Dastur, 1990. 
Esto nos lleva a una caracterización importante del fenómeno cuerpo, a saber, que a él pertenece necesariamente una permanencia en un Ahí, en un mundo determinado. Cuerpo y mundo, nuestro cuerpo y nuestro Ahí concreto son, en definitiva, un fenómeno unitario, pues nuestro existir es fáctico. No se trata, pues, de una máquina indiferente del medio en dónde ésta se encuentre, sino de que el Ahí que, según Heidegger, somos, se concreta en tanto somos nuestro cuerpo. No obstante, a diferencia de fenomenologías del cuerpo que lo postularían como condición primera de la existencia humana ${ }^{13}$, en el caso de Heidegger éste posee un puesto más bien fundado en el ser del Hombre y, por lo mismo, es secundario de acuerdo a lo que el Hombre sea en tanto Humano. Heidegger comenta en Zollikoner Seminare: «El ser-en-el-mundo en tanto tal es un cuerpear (Leiben), pero no sólo un cuerpear» (Heidegger, 1994a, p. 248), lo cual guarda íntima relación con una afirmación perteneciente a las mismas sesiones en Zollikon: «El Existir no es espacial, porque es corporal, sino que la corporalidad viva (Leiblichkeit) sólo es posible, porque el Dasein es espacial en el sentido de ordenar su espacio (einräumend)» (Heidegger, 1994a, p. 105).

El fenómeno del cuerpo no es, entonces, condición de la existencia, la constitución del espacio vital del Dasein no depende de nuestro cuerpo, sino que nuestro ser cuerpo se constituye cuando nuestro espacio se ha abierto y, por ende, corresponde a un modo de ser fundado en momentos fundamentales del existir. Nuestro ser cuerpo, por tanto, pertenece al despliegue de nuestra facticidad, vale decir, pertenece al habitar en un mundo a la luz de un poder ser. El puesto auténtico de la corporalidad es, por tanto, aquella relación concreta con el mundo ya articulado desde una posibilidad propia. ¿Cómo puede ahora ser expresado de modo más preciso este puesto en donde somos cuerpo? Pues, en que somos cuerpo en una relación con el mundo en la cual lo abierto en él nos involucra, es decir, nos apremia. En otras palabras, en el ámbito donde somos auténticamente corporales aquello que nos comparece lo hace esencialmente como apremio y no como objeto. El ente intramundano no aparece ahí ante nosotros como algo dispuesto pasivamente a ser conocido en sus características propias, sino que el ente intramundano es lo que es en esa relación inmediata fáctica, no al modo de un Gegens-tand, sino como un Gegen-drang (Cf. Heidegger, 1989, p. 157). El ente intramundano tiene, así, el carácter de lo que apremia, y es su apremio lo que constituye su manifestación más genuina para nosotros. Dicho apremio vendría a expresar el modo cómo hay entes en nuestra íntima relación fáctica, caracterizando, así, nuestro más concreto estar en medio de los entes.

Habría, entonces, propiamente entes en el mundo al interior de una relación mutua entre el poder ser del existir que los descubre y el modo cómo en dicha apertura el

13 Nos referimos, por cierto, a pensadores tales como Merleau-Ponty, cuya Phenomenologie de la perception se constituye en un análisis de la existencia encarnada. Por otra parte, Waldenfels, recepcionando y desarrollando el pensamiento de Merleau-Ponty, hace énfasis en la idea de Leibkörper, es decir, en la noción de «cuerpo vivo» encarnado materialmente en su propio mundo vital. En la actualidad, Todes (2001), atendiendo a los planteamientos tanto de Heidegger como de Merleau-Ponty, desarrolla la idea de encarnación (Fleshing o Embodiment), haciendo énfasis en el enraizamiento práctico del conocimiento para evitar una interpretación de la corporalidad de carácter idealista-transcendental. Por último, y para mencionar un tipo de fenomenología del cuerpo crítica a la desplegada por Merleau-Ponty, es importante mencionar a Michel Henry, en especial su obra Incarnation: une philosophie de la chair, así como a Schмiтz (1965), quienes igualmente destacan la primacía del cuerpo para el existir, aunque en el sentido de un cuerpo patético, esto es, de una afectividad pura, que contribuiría a una comprensión del fenómeno del cuerpo en tanto «cuerpo trascendental». Para una confrontación de ambos modos de desarrollar una fenomenología del cuerpo con el realce del cuerpo a la luz del pensamiento heideggeriano, Cf. Johnson, 2010, §§ 13-17 y §§ 25-27. 
existir se deja involucrar por ellos. Así es como en Zollikoner Seminare, Heidegger puede afirmar que «sin este ser apelado (Angesprochensein) el Hombre no podría existir» (Heidegger, 1994a, p. 180), es decir, sin este concreto habitar siendo involucrado por el ente, la existencia no sería tal, ya que pertenece a su sentido justamente la facticidad. ¿Cómo es que el cuerpo, entonces, es tal en esta relación fáctica de apremio? Heidegger afirma: "Si ustedes [los psiquiatras] fueran un espíritu puro y carente de cuerpo no podrían ver la vela como una luz brillante y amarillenta» (Heidegger, 1994a, p. 141). Interesante resulta destacar, a partir de este comentario, que el fenómeno del cuerpo comienza a ser explorado mediante el fenómeno de la percepción sensible. Ciertamente, la sensibilidad parece ser una eventual vía de acceso para comprenderlo, no obstante, tanto en estos seminarios (Cf. Heidegger, 1994a, p. 248), como en la mencionada lección sobre Nietzsche (Cf. Heidegger, 1989, p. 159), se advierte que la sensibilidad sólo parece proporcionar una caracterización parcial de la corporalidad.

Sin embargo, lo que puede ser observado desde ésta ya es relevante para nuestra discusión, a saber, que fenómenos tales como el ver sensible parecen concretar la remisión específica que ha adquirido el ente intramundano en vistas a una posibilidad de ser. La luz amarillenta de la vela es tal, es decir, es luz de esta vela que ilumina lo que quiero ver, en un contexto particular, por ejemplo, el de su uso para iluminar un espacio oscuro. En otras palabras, el ver sensible confirma a modo de contenido lo que ha sido abierto con carácter significativo en vistas a una posibilidad como es la de iluminar mi camino y no tropezar. La luz de la vela es esa luz y su color amarillo deberá adquirir su sentido concreto en vistas a esa situación determinada. Ya sea como suficiente o insuficiente, como apropiada o inapropiada para facilitar mi acceso a lo que en dicho espacio requiera alcanzar, la vela que ilumina se me presenta en cuanto vela incumbiéndome en el horizonte de una posibilidad que me encuentro concretando. Una expresión interesante aparece en este contexto, a saber, que la visión sensible parece relacionarse con una "percepción del contenido significativo» (Vernehmen des Bedeutungssgehaltes) (Heidegger, 1994a, p. 141), y esta precisa relación pareciera caracterizar nuestro «cuerpear»al modo de la sensibilidad.

Pues bien, el fenómeno del cuerpo parece acaecer fundado en el horizonte de una comprensión de ser que ha abierto un Ahí determinado en vistas a un poder ser. Esta es la perspectiva fundamental para su tematización. Por tanto, desde ella es posible entender el carácter fundado del cuerpo en el existir. No obstante, el puesto del cuerpo en esta relación de fundación parece delimitarse más aún. En el horizonte de la apertura de un Ahí, el cuerpo parece tener su puesto en la relación inmediata de incumbencia con el ente. El cuerpo acaece, entonces, en la relación primaria entre el existir y el Ahí por éste abierto. Se trata de una relación de sintonía entre abrir según lo que me incumbe y dejarme incumbir por lo que mi existir abre. En dicha relación de «correspondencia» perteneciente en esencia al existir, que por definición siempre es fáctico, acaece nuestro "estar cuerpeando», nuestro despliegue corporal, al modo de dejar aparecer lo que nos incumbe en sus contenidos de acuerdo a nuestra posibilidad. En esta relación íntima de «correspondencia» (Ent-sprechen) entre el existir que se deja apelar por lo que vitalmente le apremia, i.e., su mundo, dirá Heidegger, se funda, entonces lo corporal (Cf. Heidegger, 1994a, p. 232).

En dicha correspondencia es que la Existencia gana su concretud, se vuelve, entonces, corporal. Cuerpo habría, entones, en el movimiento ekstático del existir, y sus límites le vienen dados desde el horizonte del poder ser que cada uno de nosotros somos. Esto nos indica que el cuerpo no es una cápsula física que contiene un alma o un yo, sino más bien, que uno mismo en cuanto posibilidad de apertura de un Ahí despliega 
ese Ahí concretado al modo del apremio ${ }^{14}$. La consideración del cuerpo como objeto desatiende justamente a esta relación fáctica del existir, y en este sentido es ciega a que nuestro cuerpo es nuestro, pues, su ser es el del cuidado (Sorge).

A partir de lo anterior ya podemos ver que el fenómeno del cuerpo humano está dominado por el ser del Hombre, lo cual tiene consecuencias importantes. En primera instancia, esta pertenencia ontológica del fenómeno del cuerpo al modo del ser del ente que es corporal comienza a aclararnos el hecho de que para Heidegger no haya auténticamente una «fenomenología del cuerpo». Las razones se encuentran, por una parte, en lo que hasta ahora hemos venido discutiendo y, por otra, en que para Heidegger, como decíamos, «la »Substancia del Hombre no es el espíritu entendido como la síntesis entre alma y cuerpo, sino la Existencia» (Heidegger, 2001, p. 117).

$\mathrm{Y}$ es que hablar de una «fenomenología del cuerpo» parece implicar que es posible realizar una investigación más bien autónoma de un ente que, como veíamos, no es en sí, sino un momento de un movimiento de otro nivel: el existir. En este sentido, la expresión "fenomenología del cuerpo» parece instalarnos acríticamente en una precomprensión de lo Humano como un compuesto, en donde sí es posible aislar la corporalidad de nosotros mismos, llevándonos a desatender su naturaleza unitaria. Dicha observación no es menor si se tiene en cuenta que esto implicaría, en definitiva, el peligro de olvidar el auténtico objeto de estudio: el Hombre. Si se atiende a lo anterior, podríamos entender que una consideración del cuerpo humano no es sino un estudio del Hombre en cuanto Hombre, es decir, pertenece a lo que podríamos denominar más bien una Antropología filosófica, abocada al estudio de nosotros mismos en cuanto corporales, esto es, a nuestro modo de ser corporales. Así es como, en efecto, no habría en realidad una fenomenología del cuerpo, pues, según lo discutido, se sigue tratando en esta investigación del genuino ente que en estas consideraciones siempre ha estado en juego: el Hombre, y no de algo distinto a él.

De esta manera es que llegamos a una conclusión relevante. Una tematización existencial de nuestro cuerpo que se mueva en estricto rigor en el horizonte del ser de aquel ente al cual el cuerpo propiamente pertenece, requiere de antemano una explicitación exhaustiva de dicho modo de ser. En caso contrario, careciendo de una dirección clara y acotada de acceso, ésta siempre puede correr el peligro de violentar el fenómeno y velarlo mediante un modo de ser que le sea ajeno. Así es como podemos afirmar, en nuestro caso, que mientras una tematización radical del existir y del ser-en-el-mundo no se efectúe, el problema del cuerpo ha de quedar excluido. Mas dicha exclusión, como se advierte, no es definitiva, sino más bien "provisoria», porque el ejercicio de comprender nuestra corporalidad exige antes de nada la tarea de entenderla como nuestra, i.e., explicitarla en el horizonte de nuestro modo de ser, es decir, en su rol elaborador de mundo. Por esta razón es que Heidegger debe advertir que una tematización del cuerpo humano requiera un estudio acabado de nuestro ser-en-el-mundo (Cf. Heidegger, 1994a, p. 202), pues antes que nada ha de afianzarse el sentido de consideración desde el cual traer a la luz el modo de ser genuino de un fenómeno que por sobre todo somos nosotros mismos. En definitiva, se vuelve necesaria una lucidez metódica en los términos expuestos, en vistas a su posterior tratamiento temático. En este contexto podemos entender el hecho que Heidegger responda a la ausencia del cuerpo en Sein und Zeit sosteniendo

14 Cabe hacer notar que las descripciones acá presentes acerca del fenómeno del cuerpo se restringen a mostrar la pertenencia de éste a nuestro ser, es decir, al Dasein. No obstante, una caracterización más detallada del fenómeno cuerpo a la luz del pensamiento de Heidegger ha sido desarrollada en el artículo El cuerpo como posibilidad de la vida: el modo de despliegue del mundo concreto Cf. JoHnson, 2011. 
que «lo corporal es lo más difícil y que yo entonces justamente no sabía que más decir» (Heidegger, 1994a, p. 292). A nuestro juicio, dicha afirmación no puede sino aludir a la restricción de las consideraciones sobre el ser-en-el-mundo, en función, como sabemos, a la explicitación de lo necesario para responder a la pregunta por el sentido del ser ${ }^{15}$, lo cual deja ver el carácter provisorio y, en el mismo sentido, insuficiente (Cf. Heidegger, 2001, p. 17) de estos análisis para tratar fenómenos humanos que no incidan directamente en el fenómeno de la comprensión de ser (Seinsvertändnis) ${ }^{16}$.

En suma, y para concluir las presentes discusiones, quisiéramos, entonces, retomar las dos negaciones acerca del cuerpo con las cuales habíamos comenzado el presente artículo, para destacar la lección que podemos aprender de ellas en vistas a una comprensión del problema de nuestro cuerpo o, en estricto rigor, de nosotros mismos en cuanto corporales. Por una parte, hemos visto que la exclusión del problema del cuerpo de la analítica del Dasein no parece ser definitiva, sino que indicaría que la única vía posible para su inclusión es realzar nuestra corporalidad a la luz del sentido propio del ser del existir. Esto es lo que nos ha llevado a abordar la segunda negación, la cual parece señalar que "cuerpo» no es "cuerpo» sino en su íntima raigambre con el fenómeno de lo Humano y que un olvido de su pertenencia ontológica implica desatender desde un comienzo al auténtico ente de estudio: al Hombre. Así, ambas negaciones resultan ser una y la misma lección. Se trata de una consideración eminentemente metódica, a saber, que una investigación sobre nuestro cuerpo puede desplegarse en sentido estricto si aprendemos por vez primera a conocerlo en el horizonte de una consideración genuina del Hombre. Ambas prescriben, entonces, aprender a mirarnos desde la radicalidad del existir y, por tanto, invitan a ganar una comprensión de su modo fáctico de ser. Ambas se traducen, en definitiva, en un llamado a llevar a cabo un traslado del pensar, a ensayar una modificación radical de nuestro acceso a nosotros mismos en cuanto corporales. Así, finalizamos las presentes consideraciones afirmando que las advertencias de Heidegger tienen un genuino sentido filosófico, y, por lo mismo, no se trata con ellas de obstaculizar una comprensión del cuerpo, sino más bien de ganar una orientación previa que evite emprender estudios apresurados que terminen ocultando el asunto auténtico en juego, enceguecidos por privilegiar el progreso sólo por el progreso.

\section{REFERENCIAS BIBLIOGRÁFICAS}

Ано, К. (2009). Heidegger's Neglect of the Body. New York: State University of New York Press.

CAPuto, A. (2001). Pensiero e affettività: Heidegger e le «Stimmungen» (1889-1928). Milan: Franco Angeli.

DASTUR, F. (1990). Heidegger et la question du temps. Paris: PUF.

FRANCK, D. (1986). Heidegger et le problem de l'espace. Paris: Minuit.

15 Significativas resultan las advertencias de Ано (2009, p. 24), quien, en lugar de reprochar la ausencia del cuerpo en el pensamiento de Heidegger, más bien la contextualiza haciendo énfasis en el plan programático de la ontología fundamental que guía la totalidad de Sein und Zeit. Asimismo, HAAR (1986) у СарUто (2001) intentan entender la corporalidad en el pensamiento heideggeriano desde la disposición afectiva (Befindlichkeit).

16 Relevante en este punto es la afirmación en Zollikoner Seminare: «El ser cuerpo (Leiben) pertenece en cuanto tal al ser-en-el-mundo. Pero el ser-en-el-mundo no se agota en el ser-cuerpo (Leiben). Por ejemplo, al ser-en-el-mundo también le pertenece la comprensión de ser (Seinsverständnis), la comprensión de que yo me encuentro en la luz del ser, y la respectiva comprensión del ser de cómo el ser está determinado en la comprensión. Esta delimitación es el horizonte de la comprensión de ser. Aquí no acontece ningún ser-cuerpo (Leiben)»(HEIDEGGER, 1994a, p. 244). 
Greisch, J. (1994). «Le phénomène de la chair: un «ratage» de Sein und Zeit». En Floviral, G. (Ed.), Dimensions de l'exister. Etudes de anthropologie philosophique, vol. 40. (pp. 154-177). Paris: Éditions Peeters.

HaAR, M. (1986). «Le primat de la Stimmung sur la corpóreité du Dasein». En Heidegger Studies, vol. 2. (pp. 67-80). Berlin: Duncker \& Humblot.

Heidegger, M. (2001). Sein und Zeit. Tübingen: Max Niemeyer Verlag.

- (1994a). Zollikoner Seminare. Frankfurt a. M.: Vittorio Klostermann.

- (1989) Nietzsches Lehre vom Willen zur Macht als Erkenntnis (GA 47). Frankfurt a. M: Vittorio Klostermann.

- (1994b). Prolegomena zur Geschichte des Zeitbegriffs (GA 20). Frankfurt a. M: Vittorio Klostermann.

- (1997). Die Grundprobleme der Phänomenologie (GA 24). Frankfurt a. M: Vittorio Klostermann.

Henry, M. (2000). Incarnation: une philosophie de la chair. Paris: Éditions du Seuil.

Hoffman, P. (2006). «The Body». En Dreyfus, H., Wrathall, M. (Eds.) A Companion to Phenomenology and Existentialism. (pp. 253-262). Oxford: Blackwell Publishing.

Johnson, F. (2009). «Hacia la pregunta por la corporalidad». En Revista ALPHA, n 29. (pp. 167184). Osorno: Universidad de Los Lagos.

Johnson, E. (2010). Der Weg zum Leib. Methodische Besinnungen zu einer Ontologie der Leiblichkeit anhand des Denkens Martin Heideggers. Würtzburg: Königshausen \& Neumann.

Johnson, F. (2011). «El cuerpo como posibilidad de la vida: el modo de despliegue del mundo concreto». En Revista ALPHA, n 33. (pp. 115-130). Osorno: Universidad de Los Lagos.

Malpas, J. (2000). «Uncovering the space of disclosedness. Heidegger, Technology, and the problem of spaciality» in Being und Time. En Wrathall, M., Malpas, J. (Eds.) Enssays in Honor of Hubert L. Dreyfus, vol. 1, Heidegger, Authenticity, and Modernity. (pp. 205-228). Cambridge, Massachusetts, London: The MIT Press.

Merleau-Ponty, M. (1990). La structure du comportement. Paris: Quadrige/PUF.

- (1945). Phénoménologie de la perception. Paris: Librairie Gallimard.

Plessner, H. (1981). Die Stufen des Organischen und der Mensch: Einleitung in die philosophische Anthropologie. En Gesammelte Schriften, vol. 4. Frankfurt a. M.: Suhrkamp.

Schmiтz, H. (1965). System der Philiosophie, vol. 2. Der Leib. Bonn: Bouvier und Co. Verlag.

Todes, S. (2001). Body and World. Cambridge, Massachusetts, London: The MIT Press.

Waldenfels, B. (2004). Das leibliche Selbst. Vorlesungen zur Phänomenologie des Leibes. Frankfurt a. M.: Suhrkamp.

Universidad de La Frontera

FeLIPE JoHNSON

Temuco, Chile

felipe.johnson@ufrontera.cl

[Artículo aprobado para evaluación en noviembre de 2013] 